\title{
ALIENAÇÃO DO TRABALHO MÉDICO: TENSÕES SOBRE O MODELO BIOMÉDICO E O GERENCIALISMO NA ATENÇÃO PRIMÁRIA
}

\author{
ALIENATION OF THE MEDICAL WORK: TENSIONS ABOUT THE BIOMEDICAL \\ MODEL AND THE MANAGERIALISM IN PRIMARY HEALTH CARE
}

\author{
Lílian Soares Vidal Terra iD) ${ }_{(0000-0003-2201-7308)^{1}}$, Gastão Wagner de Souza Campos ${ }_{(0000-0001-5195-0215)^{1}}$ \\ ${ }^{1}$ Universidade Estadual de Campinas, Faculdade de Ciências Médicas, Departamento de Saúde Coletiva, \\ Campinas, São Paulo, Brasil. \\ <lilianvterra@gmail.com>
}

Resumo Com base na observação de que a perda de autonomia ante o mercado de capital e o gerencialismo contribuiu para o surgimento da alienação no trabalho médico no Sistema Único de Saúde, procuramos analisar como se dá esse fenômeno na atenção primária à saúde. Em 2015 e 2016, entrevistamos e observamos o trabalho de 15 médicos do município de Campinas (São Paulo), refletindo a respeito de autonomia profissional, clínica e gestão sobre o trabalho médico. A análise se deu por meio da construção de narrativas por núcleos temáticos, segundo referencial teórico marxista e os principais estudos acerca da profissão médica no Brasil. A partir de semelhanças nos discursos, forma de atuação e grau de alienação, dividimos os médicos em quatro modalidades: militante, sacerdote, missionário e tecnoburocrata. Concluímos que algumas dinâmicas aprofundam a alienação: o afastamento do planejamento; a fragmentação do cuidado; a predominância do modelo biomédico. Por sua vez, algumas características da atenção primária se relacionam a menor grau de alienação: a prática ampliada no território e menos focada em ações programáticas; a constituição em equipes; o diálogo e o compartilhamento de saberes; a maior participação dos usuários no próprio cuidado e no serviço de saúde. Palavras-chave processo de trabalho em saúde; atenção primária à saúde; médicos; alienação (filosofia).
Abstract Based on the observation that the loss of autonomy in the capital market and managerialism have contributed to the emergence of alienation in the medical work of the Brazilian Unified Health System, we tried to analyze how this phenomenon occurs in primary health care. In 2015 and 2016, we interviewed and observed the work of 15 physicians in the municipality of Campinas (in the state of São Paulo, Brazil), reflecting upon the professional and clinical autonomy, and the management of the medical work. The analysis was made by constructig narratives by groups of topics, following a Marxist theoretical framework and the main studies regarding the medical profession in Brazil. Taking the similarities in the discourses, ways of working and degree of alienation, we divided the physicians into four groups: activist, priest, missionary and technobureaucrat. We concluded that some dynamics intensify the alienation: the estrangement from planning; the fragmentation of care; and the prevalence of the biomedical model. In turn, some features of primary health care are related to a lower degree of alienation: the practice expanded on the territory and less focused on programmatical actions; the constitution on teams; the dialogue and the sharing of knowledge; a greater participation of the individuals in the care itself and in the health service.

Keywords work process in health; primary health care; physicians; alienation (philosophy). 


\section{Introdução}

No desafio de pesquisar, buscamos compreender a realidade a partir de um dado recorte, buscando uma aproximação cada vez maior da relação de nosso objeto com a totalidade. No presente artigo, tratamos da prática médica como expressão do desenvolvimento das relações sociais no capitalismo, reflexo da totalidade do mundo do trabalho, não nos abstendo de analisar suas particularidades.

Desenvolvemos o estudo tendo como referencial a teoria da alienação desenvolvida por Marx (2010) em seus Manuscritos econômico-filosóficos, mediante a observação das mudanças no mundo do trabalho e na sociedade desencadeadas desde a Revolução Industrial e que permearam toda a sua obra. Segundo o filósofo alemão, o trabalho é atividade vital do 'homem', por meio da qual ele se reconhece em sua humanidade, modifica seu meio, constituise em sociedade e a reproduz. No capitalismo, porém, ocorre o oposto: essa atividade torna-se estranha ao homem, afasta-o de sua humanidade. De fato,

É pelo desenvolvimento do conceito de trabalho, e no entendimento de que sob o capitalismo ele se apresenta como trabalho estranhado, que a percepção de Marx, já nesses Manuscritos, se universaliza como um sistema de caráter aberto que permite entender a gênese do pensamento e da atividade humana a partir da interação que estes mantêm com a natureza, e de como esta interação sintetiza-se tanto na sociabilidade do natural quanto na progressiva autonomia da consciência em face dessa determinabilidade (Ranieri, 2001, p. 29).

$\mathrm{Na}$ análise dos processos históricos, observa-se que relações de trabalho alienadas estiveram presentes em sociedades de formação pré-capitalista, não podendo, no entanto, ser generalizadas (Lukács, 2003; Ranieri, 2001). Porém, na medida em que o nível tecnológico do trabalho aumenta e o homem passa a produzir excedente econômico apreciável, surgem condições para que alguns se abstenham de produzir e desfrutem do ócio, inaugurando a divisão entre planejamento e execução. A alienação foi-se aprofundando na sociedade, portanto, à medida que a divisão social do trabalho e a consequente formação de classes se sedimentavam.

Com a evolução histórica, já na forma como o trabalho se manifesta no capitalismo, no qual o poder social - apesar de produzido pelos homens separa-se deles e os subjuga (Ranieri, 2001), a alienação outrora incipiente torna-se mais explícita. Na época dos escritos de Marx, no processo de trabalho da nascente indústria, os trabalhadores eram desapropriados de sua produção e passavam a não se identificar com ela: a apropriação privada dos meios de produção e a transformação da força de trabalho em mercadoria implicaram um afastamento ou estranhamento entre aquele que produz e aquilo que é 
produzido. Depreendem-se, como consequência desse processo, quatro manifestações da alienação conforme descritas por Marx (Balibar, 2014; Marx, 2010; Meszáros, 2016; Ranieri, 2001): alienação do produto, em que, apartado do planejamento, o homem não reconhece o resultado de sua própria produção; alienação na atividade produtiva, em que o homem perde o controle sobre o processo produtivo, de forma que o trabalho deixa de ser predominantemente a realização, a livre afirmação de si, para se tornar predominantemente subsistência; alienação de si mesmo, uma vez que a vida humana em torno de um trabalho voltado à subsistência submete a humanidade "à animalidade, as faculdades intelectuais às necessidades" (Balibar, 2014, p. 236), alienando o homem de sua própria natureza humana; por fim, a alienação da humanidade, em que, alheio de si mesmo, o homem torna-se incapaz de se reconhecer no outro, privando-o da sociabilidade.

Assim, observa-se que, ao longo do processo de produção capitalista, o homem progressivamente perde autonomia sobre si mesmo, como se toda a sua existência fosse direcionada por uma instância alheia, reificada. Essa outra instância, fruto da criação humana - o Mercado, o Estado, a Empresa, a Ciência -, toma forma, adquire subjetividade e o subjuga (Konder, 2009; Ranieri, 2001; Lukács, 2003). Tornamo-nos uma sociedade mediada pelo consumo, em que as relações entre pessoas se transformam em relações entre objetos estranhados. Essa forma de sociabilidade guarda afinidade com a medicina moderna de mercado, que coloca o corpo como mercadoria, tanto quanto os insumos necessários para manejar esse corpo, e nessa prática os indivíduos são alienados de seu próprio corpo, de seu autocuidado.

Podemos dizer que o desenvolvimento da profissão médica é marcado, desde a modernidade, pela alienação. A alienação dos sujeitos e comunidades de seus corpos e de seu processo de adoecimento e cura progressivamente evolui para a alienação no trabalho médico. No século XVIII, o pensamento iluminista permite a construção de novos conhecimentos que substituem a perspectiva sobrenatural de saúde e doença atrelada à Igreja, avançando a concepção do corpo como um mecanismo regido pelas leis naturais do universo, uma máquina à qual apenas o médico tem acesso, e estabelecendo uma nova relação entre doenças e anatomia e entre a medicina e a sociedade (Mota e Schraiber, 2014). Institui-se o paradigma biomédico, de reificação do sujeito com redução de suas dimensões subjetiva e social. Seguem-se a Revolução Industrial e o avanço tecnológico, com o aumento da expectativa de vida, a redução da morbimortalidade por doenças infectocontagiosas, a redução da mortalidade infantil, ao mesmo tempo que se ampliam a submissão e o controle dos corpos. O desenvolvimento tecnocientífico, que permitiu o avanço social no que se refere a adoecimento e mortalidade, culminou no fracionamento do corpo, tornado coisa para a prática médica. 
Com o avanço da ciência, a profissão médica começa a se modificar também no sentido da especialização, cada vez mais aprofundada, e nessa nova realidade a prática liberal e autônoma vai perdendo espaço. O médico já não consegue trabalhar sozinho, necessita de outros que detenham um conhecimento complementar e dos meios de produção cada vez mais complexos e caros (Donnangelo, 2011). Nessa nova estrutura, sua prática passa a ser, em grande parte, ditada pelo capital investido no complexo médico industrial; e mesmo o consultório privado, no início do século XX local de prática liberal, torna-se progressivamente um consultório empresa (Schraiber, 2008).

Como resultado, desenvolvem-se na prática médica os quatro fenômenos da alienação, conforme descritos por Marx (Balibar, 2014; Marx, 2010; Meszáros, 2016):

- Do produto, pois não há clareza a respeito do que seria o produto do trabalho médico. Na forma de gerenciar esse trabalho, privilegiam-se a consulta e o procedimento em detrimento do cuidado, não passível de ser computado em planilhas e indicadores de produtividade;

- Na atividade produtiva, que ante a perda progressiva de autonomia já não é mais planejada pelo médico, assim como seu tempo, ou a razão da tarefa a ser executada;

- De si mesmo, uma vez que nessa lógica produtivista o médico se torna incapaz de ver sua humanidade refletida em seu trabalho. A alienação do produto e da atividade o leva a se alienar de si mesmo em uma prática que não lhe faz sentido, tornando o trabalho um sacrifício;

- E por fim, alienado de si mesmo, de sua humanidade refletida no trabalho, o médico se aliena de seus semelhantes, resultando na tão frequente desumanização do trabalho em saúde.

A alienação é, no entanto, um fenômeno dialético. Meszáros (2016) afirma que alienação é um conceito intrinsecamente dinâmico, que necessariamente implica mudança, de modo que irá se apresentar de forma diversa em diferentes loci de trabalho e até mesmo num mesmo indivíduo. A atividade alienada produz não só a 'consciência alienada', mas também a 'consciência de ser alienado', e a partir dessa consciência a necessidade de superação. Para o autor, a única força capaz de suplantar na prática a alienação da atividade humana seria a própria atividade humana autoconsciente: os homens, como produtos de uma sociedade alienada, precisam se tornar autoconscientes (Meszáros, 2016). Ademais, os sujeitos são coproduzidos, isto é, são resultado dos fatores que operam no contexto, das instâncias determinísticas, e também de fatores intrínsecos que resultam de seus processos subjetivos e de sua capacidade singular de agir sobre esse mesmo contexto (Campos, 2010).

Assim, partimos da reflexão de que alguns fatores abriram caminho para a alienação no trabalho mesmo no campo da saúde e no serviço público, onde o trabalho mais relacional, mais de troca entre pessoas, protegeria os trabalha- 
dores desse fenômeno. Tais fatores são a submissão da medicina ao mercado de capital, tanto na formação quanto na atuação, em que a prática é ditada pelo que é produzido no complexo médico industrial, na forma de consensos e diretrizes que nos direcionam a consumir medicamentos e procedimentos (Donnangelo, 2011), mesmo carecendo de evidências concretas. Também o modelo biomédico, que ao fragmentar o corpo desumaniza o paciente, o qual passa a ser um objeto defeituoso sobre o qual se deve intervir. E por fim a organização dos serviços, fortemente influenciada pela administração científica, pelos moldes fordistas e toyotistas, que afastam o trabalhador do planejamento de suas atividades e o alienam em uma parte da cadeia de produção (Campos, 1997; Konder, 2009; Ranieri, 2001; Marx, 2010).

Há uma forte tensão entre esse modelo de prática médica e o modelo de saúde pública brasileiro, em que o poder médico é constrangido pela valorização de outros saberes, entre eles o do próprio paciente, outrora relegado à condição submissa de mero espectador do próprio processo saúde-doençacuidado (Campos, 2010), e pelo entendimento de que corpo não é uma máquina, mas um sujeito dotado de complexidades e inserido em determinado contexto de vida. O Estado não só procura incentivar, por meio de políticas públicas, um outro olhar sobre saúde, menos centrado na biomedicina, como medeia as relações com o capital dando acesso a uma população que seria excluída.

Assim, o estudo que originou este artigo pretendeu explorar a dialética da alienação no trabalho médico. Trata-se de um recorte das relações de trabalho na sociedade capitalista, entre elas o trabalho em saúde, com foco no Sistema Único de Saúde (SUS), especificamente o trabalho médico na atenção primária do SUS em Campinas (São Paulo). Como um recorte, pretendeu ser representativo da totalidade, ela mesma sempre uma síntese de elementos ou partes.

\section{Analisando o trabalho com base no discurso do trabalhador e na observação etnográfica da prática médica}

A pesquisa aqui apresentada foi desenvolvida por metodologia qualitativa, com entrevistas e observação participante de 15 médicos da atenção primária à saúde (APS) de Campinas. Seu referencial foi o materialismo histórico dialético, segundo o qual se compreende que para se fazer uma análise de qualquer fenômeno social é necessário partir de sua observação na realidade concreta, analisando suas origens no processo histórico e de construção pelo qual ele passou, além de investigar as forças envolvidas e os movimentos dialéticos que contribuíram para o seu desenvolvimento. Não se pretendeu, com base nesse método de análise, produzir uma verdade final, pois em qualquer observação da realidade a subjetividade do observador, ou seja, seu olhar sócio-historicamente construído, estará implicado. Não é possível, 
portanto, haver uma realidade isenta e neutra na qual nosso olhar ou nossa ação humana não estejam envolvidos (Minayo, 2006). Qualquer produção humana, por mais que se pretenda objetiva, será dialética, será objetivação e subjetivação. A pesquisa científica não seria diferente.

Optamos, assim, pela realização de uma investigação baseada na tradição do que se convencionou denominar de pesquisa-intervenção, mais especificamente pela metodologia estudada por Rocha e Aguiar (2003). Nela, pesquisador e campo de pesquisa estão articulados, e o resultado é produzido conjuntamente por meio dessa dialética de subjetivação e de objetivação, sem que se deixe de analisar, ao final, os impactos da intervenção do pesquisador no resultado das investigações. De forma convergente, várias linhas de investigação legitimam a participação dos sujeitos em diversos momentos do ato de pesquisar por meio do estabelecimento de colaboração entre pesquisadores e pessoas envolvidas com o objeto de estudo, sejam eles os usuários dos serviços, sejam profissionais/gestores ou a comunidade (Bulmer, 1977; Thiollent, 1996; Passos e Barros, 2000; Paulon, 2005; Guba e Lincoln, 1989; OnockoCampos e Furtado, 2008). Trata-se de diferentes métodos de abordagem que, de maneira similar, permitem a interação entre os interesses do pesquisador e os dos grupos diretamente implicados na condução das práticas investigadas. Segundo Aguiar e Rocha,

A relação pesquisador/objeto pesquisado é dinâmica e determinará os próprios caminhos da pesquisa, sendo uma produção do grupo envolvido. Pesquisa é, assim, ação, construção, transformação coletiva, análise das forças sócio-históricas e políticas que atuam nas situações e das próprias implicações, inclusive dos referenciais de análise. É um modo de intervenção, na medida em que recorta o cotidiano em suas tarefas, em sua funcionalidade, em sua pragmática - variáveis imprescindíveis à manutenção do campo de trabalho que se configura como eficiente $\mathrm{e}$ produtivo no paradigma do mundo moderno (Aguiar e Rocha, 1997, p. 97).

Desse modo, pesquisador e campo de pesquisa estiveram articulados, e o resultado foi produzido conjuntamente. Como médica e inserida na mesma rede que os sujeitos da pesquisa, a pesquisadora principal esteve muito envolvida, e suas representações permearam claramente a pesquisa, não havendo, no entanto, conflitos de interesses.

Por se tratar de uma intervenção, abordamos de forma contínua as etapas que compuseram sua produção: a revisão bibliográfica; a contextualização, com breve estudo teórico acerca da história da profissão médica no Brasil e sua inserção na atenção primária; a intervenção analítico-reflexiva e a análise dos dados produzidos.

A intervenção analítico-reflexiva foi conduzida por meio de entrevistas e observação participante, em que, ao falar sobre suas práticas e sua relação 
com o trabalho, os participantes eram provocados a refletir e, consequentemente, a tornar o trabalho menos automatizado, logo, mais autoconsciente. As entrevistas foram semiestruturadas, com um roteiro inicial pelo qual fomos navegando conforme o discurso dos médicos, com momentos de fala livre e momentos de direcionamento, quando necessitávamos investigar algum ponto específico. Na observação participante, por sua vez, buscamos confrontar o discurso dos médicos com sua prática, de modo a procurar alguma incoerência e observar, nos sujeitos da pesquisa, como se dava essa dialética objetivação - da sua prática - e subjetivação - do seu discurso. Para o registro das observações, fizemos uso de diários de campo.

A análise de dados ocorreu ao longo de todo o processo de intervenção. Uma vez coletado o material, o caminho percorrido foi o da transcrição, seguido de construção, análise e interpretação de narrativas juntamente com os diários de campo. Nessa construção, consideramos que, "ao analisar e interpretar informações geradas por uma pesquisa qualitativa, devemos caminhar tanto na direção do que é homogêneo quanto no que se diferencia dentro de um meio social" (Gomes, Romeu, 2010, p. 80). Portanto, inferimos, na transcrição das entrevistas, os núcleos de sentido em que se agrupam as falas dos participantes (Gomes, Romeu, 2010), ou seja, procuramos agrupar nos discursos o que era comum e o que era dissenso, para enfim chegar às categorias análise da pesquisa descritas na introdução e que são desenvolvidas a seguir.

Como método de interpretação, Minayo (2006) sugere o diálogo entre hermenêutica e dialética, ou compreensão e crítica, a partir do qual busca-se a lógica interna dos fatos, relatos e observação, situando-os no contexto dos atores e produzindo-se um relato em que os atores se reconheçam (Minayo, 2006). Nessa etapa, o material decomposto para a produção da narrativa foi novamente sintetizado em torno de um texto trabalhado juntamente com o referencial teórico.

O objetivo da pesquisa aqui descrita foi analisar o processo de alienação no trabalho médico, com reflexão sobre o cuidado, os modos de gestão e as relações dos trabalhadores. Para tanto, foram selecionadas por amostra intencional duas unidades de dois dos cinco distritos de saúde de Campinas, buscando em cada distrito uma unidade que adotasse um modelo predominante de saúde da família e uma unidade com funcionamento biomédico tradicional, no estilo ambulatorial, e cada qual com maior ou menor participação dos profissionais na gestão. Todos os médicos que atuavam como clínicos ou médicos de família nessas unidades foram convidados a participar. No final, obtivemos 15 participantes, uma recusa e duas justificativas de impossibilidade de participação.

O município de Campinas, onde foi desenvolvida a pesquisa, tem tradição no SUS e contribui significativamente para a formulação das políticas de saúde no Brasil. Sede de uma região metropolitana, contava, em 2016, com 
população estimada pelo Instituto Brasileiro de Geografia e Estatística em 1.173.370 habitantes (Instituto Brasileiro de Geografia e Estatística, 2016). Possui sistema de saúde complexo, com extensa rede de serviços, instâncias de gestão e controle social. Apesar de algumas tentativas de implantação da Estratégia Saúde da Família (Campos, 1999; Colegiado de Gestores da Secretaria Municipal de Saúde de Campinas, 2001), ainda apresenta um modelo híbrido, com enfermagem de nível superior e técnico, agentes comunitários de saúde atuando no atendimento a todos os gêneros e ciclos de vida e médicos atuando por especialidades (clínica, pediatria e gineco-obstetrícia).

No que se refere ao trabalho médico, o município é representativo do contexto nacional, com algumas particularidades. Apresenta alta concentração de médicos - razão de 5,11 médicos por habitante (2,45 na região metropolitana) (Conselho Regional de Medicina do Estado de São Paulo, 2012), porém tem dificuldade de atrair esses profissionais para atuar no SUS $(51 \%$ dos profissionais do município ou 1,58 por mil habitantes) (Colegiado de Gestores do Departamento Regional de Saúde VII, 2016). Trata-se da mais baixa proporção de médicos-SUS do estado de São Paulo, o que sugere que a dificuldade em se fixarem médicos na rede pública de Campinas está mais relacionada à maior atração pelo mercado privado, o que pode ser um dos motivos que levaram o município a aderir ao Programa Mais Médicos.

Em concurso público realizado em 2014, a Secretaria municipal de Saúde traçou o perfil dos profissionais ingressantes, o que revelou que dentre os contratados como médicos de família (generalistas e especialistas em medicina de família e comunidade) apenas 38\% tinham intenção de seguir carreira no SUS Campinas. Dentre os contratados como clínicos, dos quais $67 \%$ pretendiam trabalhar na rede de urgência e emergência e somente $17 \%$ na atenção primária, 74\% tinham intenção de seguir carreira no SUS Campinas.

\section{Quatro modalidades de trabalho médico na atenção primária à saúde}

Dentre os 15 participantes, seis eram homens e nove mulheres. Quatro deles eram cubanos participantes do Programa Mais Médicos (PMM) em missão temporária no Brasil na atenção primária do município de Campinas e impedidos de trabalhar em outros serviços. Dentre os 11 restantes, três atuavam somente na APS de Campinas. Além deste serviço, outros quatro trabalhavam em serviços de emergência do SUS, entre 12 e 48 horas semanais, três como docentes de cursos de medicina e uma atendendo em ambulatório de especialidades do SUS e consultório privado.

Os entrevistados situavam-se na faixa etária dos 26 aos 55 anos e tinham de três a trinta anos de formação, com a média de 14 anos. A maioria graduou-se em faculdades públicas (11 dos 15). Sua jornada de trabalho na atenção primária variava entre 24 e 36 horas, sendo que essa variação não 
guardava relação com a quantidade de atividades que exerciam durante esse período. A maioria atuava como clínico geral, atendendo somente os adultos das equipes de saúde da família (EqSFs), como é característico da forma de organização do município. Apenas um deles exercia a função de médico de família. Mesmo os médicos cubanos do Programa Mais Médicos, cujo contrato de trabalho contempla atendimento à família, atendiam somente clínica médica.

No que se refere ao modo de gestão das unidades, alguns pontos podem ser destacados. Espaços democráticos de gestão foram encontrados em todas as unidades, sem que, no entanto, houvesse participação dos médicos em todos eles, e sem que eles se configurassem, de fato, em democratização da gestão. Em um dos distritos estudados, uma unidade tinha colegiado gestor cujos membros, de todas as categorias profissionais, faziam rodízio na participação, enquanto outra não dispunha desse espaço.

Uma das unidades havia passado recentemente por troca de gestão. Nessa troca, modificou o modelo de assistência aos pacientes e reduziu a participação dos médicos na organização do serviço, ainda que o gestor mantivesse abertura para diálogo com os profissionais. Todos esses achados foram relevantes para a análise de um perfil de médicos. Ressaltamos que ainda que as unidades fossem diferentes quanto ao modo de gestão, o que nos levou a selecioná-las para buscar diferenças entre os profissionais, no que se refere ao trabalho médico a forma de atuação se mostrou predominantemente homogênea. Enquanto algumas unidades funcionavam em um modelo mais programático e fragmentado e outras em um modelo mais semelhante ao pretendido pela Estratégia Saúde da Família, com base territorial e atendimento longitudinal, todos os médicos praticavam a medicina de forma predominantemente ambulatorial, isto é, as consultas correspondiam à maior parte de sua carga horária, o que caracteriza uma prática mais próxima do paradigma biomédico, algo também explicitado nas falas dos entrevistados.

No decorrer da pesquisa, encontramos médicos com muitas semelhanças na maneira como falavam e lidavam com a objetivação de seu próprio trabalho, nas formas de alienação e de realização da atividade profissional, na visão que tinham do contexto e ainda no modo como se relacionavam com outros colegas de trabalho e com a instituição. As características comuns dos grupos de médicos fizeram com que os dividíssemos em quatro modalidades de relação com a prática médica na atenção primária: o militante, o sacerdote, o missionário e o tecnoburocrata.

A modalidade militante correspondeu a cinco médicos distribuídos nas quatro unidades estudadas, que externaram um projeto comum no sentido ideológico, ético e político, como estratégia para superarem constrangimentos do contexto, da instituição médica, do SUS e de sua própria formação. Eles apresentavam uma visão crítica do papel do médico na construção do sistema 
de saúde, seja de forma restrita ao seu local de atuação, seja de forma mais ampla, com referências à política de saúde, ao sistema e à formação em saúde. Também apresentaram autocrítica em relação à visão que a sociedade tem dos médicos, julgados pela imprensa e em muitos círculos como mercenários e desumanos. Por isso os chamamos militantes, como muitos deles se identificaram.

Durante as entrevistas, mostraram-se bastante comunicativos e foram muito abertos à observação participante, compartilhando a condução de casos durante consultas, visitas domiciliares e discussão de assuntos diversos nas reuniões. Também se mostraram mais implicados com o trabalho e se declararam mais realizados com sua carreira profissional, ainda que com muitas críticas à forma de organização dos serviços ou à atual conjuntura do SUS. Em sua atuação, embora focassem seu trabalho nos pacientes, procuravam produzir ações mais abrangentes sobre o território e a comunidade, compartilhando sua visão acerca do sistema de saúde e da organização do serviço com seus colegas e usuários da rede e ocupando outros espaços além da prática de consultório: na universidade, nos conselhos de saúde, nos colegiados de gestão, nas próprias reuniões de equipe de saúde da família ou no grupo de gestão do cuidado - o que se verificou com somente um médico dos outros grupos.

Outros cinco puderam ser caracterizados por um exercício da medicina como sacerdócio, algo que foi identificado em declarações e pela postura desses profissionais ao identificarem seu trabalho como algo humanitário, com sentido de ajuda ao outro. Essa modalidade de atuação, a que denominamos sacerdotes, foi composta por médicos das quatro unidades de saúde estudadas.

Observamos que o foco principal de seu trabalho também era o paciente, mas a reflexão sobre política de saúde, ou sobre o potencial de modificação do território e de construção de autonomia da comunidade, que são diretrizes da atenção primária, pouco aparecia em seus discursos. Não apresentavam autocrítica acerca da relação dos médicos com a sociedade e tendiam a culpar atores externos - a imprensa, a instituição, o governo - pela imagem do médico, pelos insucessos da clínica, pelas dificuldades com o trabalho em geral. Percebemos que eram médicos implicados e dedicados ao trabalho, porém não procuravam participar do planejamento de suas ações, ainda que se mostrassem insatisfeitos com a forma de gestão e com a estrutura. Aceitavam que a organização do serviço fosse dada pela gestão, hierarquicamente, focando suas energias no ambulatório, onde investiam em um bom vínculo com os usuários, considerados agentes passivos da relação médico-paciente, e na qualidade técnica de sua prática. Entretanto, eram ativos na forma como exerciam o poder médico, respaldando-se no saber técnico, para cujo desenvolvimento dedicavam muito de seu tempo.

Os médicos cubanos entrevistados, os quais denominamos missionários, como alguns se intitulavam, estavam em missão no Brasil desde 2014 e atuavam em duas das quatro unidades estudadas: uma maior, de modelo mais ambula- 
torial, e outra menor, com uma gestão mais aberta à participação e ações um pouco mais voltadas para o território. Todos possuíam formação em medicina geral integral (MGI), período obrigatório de dois anos de atendimento na atenção básica de saúde após a graduação em medicina. Esse perfil de médicos também se subdividiu entre alguns com características mais comuns ao grupo militante e outros ao grupo sacerdote, subdivisão que coincidia com a unidade onde estavam atuando, o que nos fez refletir sobre estarem em grande parte condicionados pela estrutura. A percepção que tiveram da medicina no Brasil e a satisfação em poderem atuar no país mostravam-se intimamente relacionadas a seu local de atuação, seja mais de proximidade do planejamento e também do modelo cubano, seja mais ambulatorial e programática, planejada unilateralmente pela gestão. Apesar de eles terem em comum com os militantes o fato de se sentirem executores de um projeto coletivo, não pareciam elaborar críticas ou exercer protagonismo político para alterar a gestão ou a política de saúde, o que pode se dever ao fato de serem médicos estrangeiros em missão internacional e temporária.

Finalmente, um dos médicos participantes do estudo não se identificou propriamente com nenhum dos outros perfis, apresentando-se como alguém alienado em relação à sua própria prática, ao contexto institucional e aos demais trabalhadores, de modo que o denominamos tecnoburocrata. Atuava na atenção primária como clínico, o que não coincidia com sua especialidade. De poucas palavras, pouco participava da entrevista ou da observação. Porém, a gestora da unidade nos relatou que a qualidade do atendimento desse médico e sua participação na rotina da unidade melhoraram durante a observação participante, o que foi notado pelo restante de sua equipe multidisciplinar. Ele também não apresentava uma opinião formada acerca da repercussão das políticas de saúde sobre o trabalho médico ou sobre a visão que a sociedade brasileira tem da categoria médica. Aparentava cansaço e não se mostrava implicado no trabalho, tampouco realizado, apesar de afirmar sê-lo.

As diferentes modalidades de alienação se espalhavam entre os vários serviços, de modo que não pudemos inferir correlação de determinação entre modelo de gestão e local de trabalho com maior ou menor envolvimento com o trabalho ou com o grau de alienação dos médicos. Mas o maior grau de autonomia dos médicos, sua maior presença em espaços democráticos de gestão e organização menos burocratizada e fragmentada do serviço foram relacionados a maior grau de reflexão sobre o trabalho e sobre o contexto - o que ficou claro na observação do grupo missionário, justamente por este ser mais homogêneo, e no discurso dos médicos de uma unidade que havia passado por dois modelos diferentes de gestão. Também pareceu haver forte relação entre docência e formação em saúde coletiva e maior apropriação sobre o trabalho, mais comuns ao grupo mi- 
litante, percebido como o mais autoconsciente. A média de idade, tempo de formação e tempo de serviço também não apontaram para nenhuma correlação com o grau de alienação.

\section{As tensões sobre o modelo biomédico e o gerencialismo no trabalho médico na APS}

As narrativas produzidas com base nas entrevistas e nos diários de campo foram analisadas segundo dois núcleos de sentido: autonomia profissional e gestão sobre o trabalho médico; e a atenção primária à saúde como local de uma prática reflexiva.

A autonomia do médico apareceu como uma importante questão, principalmente em relação ao planejamento do serviço e à gestão da rotina de trabalho e em menor grau ante os preceitos científicos. No que se refere ao planejamento e gestão, foram muitas as queixas, principalmente sobre a ordenação de suas próprias atividades, em geral restritas ao consultório e ao tempo rígido de consulta. Neste quesito, os grupos apresentaram-se semelhantes, o que pode se dever ao fato de que, ainda que alguns a contragosto, exerciam uma prática centrada no consultório, estruturada predominantemente pelo paradigma biomédico. Neste modelo de gestão, os médicos não têm controle sobre quais demandas estão sendo agendadas e se os pacientes que necessitam estão conseguindo acessar o serviço, o que foi criticado por todos os médicos participantes do estudo, sendo o tempo reduzido para a consulta a principal questão. Este achado corrobora a afirmação de Campos (2010), Gomes (Gomes, Rogério, 2010) e Souza (2015) de que há uma tendência ao gerencialismo mesmo no sistema público, inspirado em moldes fordistas, com definição das metas e da organização do trabalho unilateralmente pela gestão. Ainda assim, os médicos entrevistados observaram que tinham autonomia para o exercício da prática dentro do consultório, no contato com os usuários dos serviços.

A respeito dessa prática supostamente liberal e autônoma, somente um médico questionou o uso de protocolos no direcionamento do trabalho médico, referindo-se ao fato de que se o trabalho médico fosse completamente guiado por protocolos os médicos seriam máquinas, e refletindo sobre o fato de muitas vezes os protocolos e diretrizes serem produzidos em um contexto diferente do de sua atuação, com base no estudo de populações também distintas daquela na qual atuava. Alguns médicos militantes fizeram reflexões de conteúdo semelhante durante debates, condução de casos e reuniões, mas não no discurso durante a entrevista, e os demais médicos sequer problematizaram o tema.

Donnangelo (2011) e Gomes (Gomes, Rogério 2010) observam que, de fato, é comum os médicos se queixarem das regras impostas pela gestão, a que Donnangelo denomina interferências externas, mas não se ressentirem daquelas que são ditadas pelos próprios pares e por suas instituições, as interferências 
internas, exemplificadas nos consensos e diretrizes emitidos pelas associações médicas. Os médicos participantes do estudo aqui apresentado não definiram essas interferências internas como perda de autonomia.

A respeito das consequências da falta de autonomia de que se queixaram, algumas reflexões foram produzidas pelos médicos. Segundo a maioria dos militantes, a falta de autonomia ou de participação no planejamento do serviço se refletia em menor efetividade do trabalho médico, em resultados mais limitados. De acordo com uma das entrevistadas do grupo militante, a limitação decorria da desconexão entre o que se estava produzindo de cuidado nos atendimentos individuais e as reais necessidades do território, que poderiam ser atendidas por outros tipos de intervenção. Essa reflexão não foi feita pelos médicos dos demais grupos, que tampouco procuram participar do planejamento de ações, mesmo quando havia abertura por parte da gestão.

$\mathrm{Na}$ análise acerca do tema da autonomia, percebemos que os médicos que tinham formação em saúde coletiva, medicina geral integral ou medicina de família e comunidade pareciam desfrutar de maior autonomia em comparação com os demais. Este achado poderia se dever ao maior conhecimento sobre ferramentas de gestão do trabalho trazido por essa formação, mas também poderia sugerir que essa formação seria buscada por médicos que já têm um perfil compatível com a atenção primária, o que facilitaria a inserção do profissional e a busca por autonomia. Os médicos que participam do planejamento aparentam estar mais implicados com o trabalho, sem que possamos afirmar que a participação traz maior implicação ou se ocorre o oposto. Ainda assim, de forma semelhante a todos os médicos participantes do estudo, a estrutura parecia constrangê-los, em maior ou menor grau, a somente executarem as tarefas que lhes eram delegadas, principalmente o atendimento de consultas individuais.

Ainda que a maior parte da carga horária de todos os participantes do estudo se concentrasse no consultório, e que a maioria tenha declarado que não conseguia planejar sua rotina para atuar de forma mais ampla, a forma de atuação dos médicos não chegava a ser completamente homogênea, isto é: ainda que se buscasse formatar a prática médica em determinado arranjo biomédico, havia contradições internas do SUS Campinas que permitiam que os profissionais tivessem certa liberdade na configuração de seu processo de trabalho. Assim, no decurso da pesquisa observamos que uma prática ampliada no território, menos focada em ações programáticas, esteve relacionada com um trabalho com menor grau de alienação. A busca por essa forma de atuação pôde ser percebida principalmente o grup mMilitate, e apareceu em momentos diversos dos relatos quando abordavam outros assuntos: a questão da autonomia na gestão do próprio trabalho; o trabalho em equipe interdisciplinar; as políticas de saúde; a influência de seu modo de pensar no trabalho conjunto da unidade; sua realização pessoal etc. Percebemos, em alguns dis- 
cursos, a valorização do cuidado integral na APS em oposição à fragmentação característica do nível secundário de atuação que, segundo um entrevistado, apesar de ter sua importância, não deve sobrepor sua lógica a todos os níveis de atenção à saúde. A valorização desse lugar e forma de atuação esteve relacionada à ocupação dos espaços coletivos do SUS Campinas, desde a reunião de equipe de saúde da família até o controle social.

Campos (2013) e Peduzzi (2002) afirmam que a constituição de espaços coletivos e compartilhados reduz a hierarquização e democratiza o trabalho em saúde. O diálogo e o compartilhamento de saberes provocam reflexão entre os trabalhadores, principalmente quando há um esforço contínuo de alguns membros da equipe interdisciplinar, em um exemplo de atividade humana autoconsciente favorecendo a superação do trabalho alienado. Porém, a existência desses espaços democráticos compartilhados por sujeitos em diferentes graus de alienação e autoconsciência não basta para provocar essa superação. O próprio desinteresse pelo espaço ou pelo diálogo que aí ocorre aparece como uma manifestação da alienação que dificulta sua transcendência.

Nesse sentido, foram observadas diferenças mesmo entre as reuniões das equipes multidisciplinares dos médicos dos diferentes grupos. As reuniões das EqSFs em que havia médicos sacerdotes eram usadas predominantemente para a discussão de casos, seguida pelo planejamento de algumas atividades da equipe, como grupos e visitas domiciliares, além de alguns informes passados pela coordenação. Por sua vez, o grupo militante se mostrava ativo e geralmente conduzia as reuniões, discutindo casos clínicos, mas também refletindo sobre outras questões referentes a processo de trabalho ou atuação da equipe no território adscrito. Interessante observar que os militantes debatiam e levantavam questões acerca do processo saúde-doença-cuidado dos pacientes, coconstrução de cuidado e autonomia, medicalização e normatização excessiva da medicina durante as reuniões, trazendo até mesmo discussões sobre maneiras para se estabelecer um limite às intervenções dos serviços de saúde, algo não observado entre os demais participantes da pesquisa. Os espaços de troca, portanto, dentre os quais podemos ainda incluir o apoio matricial em saúde mental, pareceram provocar os médicos a refletir sobre as relações de poder e sobre sua prática clínica, questionando o modelo biomédico.

O trabalho na atenção primária à saúde também pareceu provocar os profissionais a refletirem sobre seu papel e o papel da ciência médica na sociedade, corroborando, no discurso dos médicos, a hipótese de Schraiber e Mendes-Gonçalves (2000). Oito dos 15 médicos participantes da pesquisa mostraram-se capazes de refletir, com maior ou menor profundidade, acerca da medicalização, da institucionalização e da dependência excessiva das pessoas dos profissionais ou dos serviços de saúde. Além disso, os profissionais cuja prática se aproximava mais do modelo de atenção primária à saúde, com inserção na comunidade e aprofundamento do vínculo com os usuários 
dos serviços, imbricando-se no território para a partir do diagnóstico local construir sua prática, mostravam-se mais autoconscientes e ao mesmo tempo pouco confortáveis em seu papel como normatizadores. Mesmo no que diz respeito à alienação da prática ante o complexo médico-industrial ou à relação saúde-sociedade mediada pela mercadoria, o trabalho na APS, desde que de fato compartilhado e democrático, mostrou-se mais próximo de uma prática reflexiva e crítica. A medicina de comunidade e a clínica ampliada constituíram-se, dessa forma, num esforço simultâneo para aumentar o coeficiente de autonomia e de autocuidado dos usuários e comunidades e promover reflexão entre os profissionais de saúde.

Em contrapartida, entre médicos de características sacerdote e tecnoburocrata, houve menos questionamento a respeito dos paradigmas da prática biomédica e menor horizontalidade nas relações com a equipe multidisciplinar e com os usuários dos serviços. Entre eles, havia uma clara hierarquização entre médico e paciente: médico é o detentor de um conhecimento que deve passar ao paciente, que por sua vez deve assimilar o que está sendo ensinado e cumprir o regime de vida prescrito a fim de evitar o adoecimento ou as complicações dele advindas. Ainda que houvesse frustração diante do insucesso na adesão de pacientes ao tratamento recomendado, não se verificou entre esses médicos um questionamento acerca de sua própria atuação além da técnica, que buscavam manter sempre atualizada. Havia, assim, a visão de uma medicina neutra, apolítica e a-histórica, que exerciam com dedicação.

Com base nesses achados, refletimos sobre o fato de que tanto a atenção primária, com o tempo, pode ter permitido a esses médicos desenvolver uma prática mais reflexiva, como o próprio compartilhamento de uma prática mais reflexiva pode ter provocado tais mudanças nas equipes de saúde e nos próprios profissionais. E por mais que tenhamos percebido diferentes graus de alienação nos participantes da pesquisa, verificamos em geral um compromisso com a produção de cuidado e uma identificação e valorização da própria profissão. Enfim, percebemos que os médicos participantes do estudo tinham boa capacidade de refletir sobre o trabalho e de exercer autoconsciência, especialmente os que estudaram saúde pública, seja em Cuba, seja no Brasil.

\section{Considerações finais}

Ao retomar nossos objetivos iniciais e amparados por Campos (2013), Peduzzi (2002) e Mota e Schraiber (2014), concluímos que algumas dinâmicas de trabalho da atenção primária em saúde potencializam uma atividade menos alienada. No SUS Campinas, ressaltamos o trabalho multiprofissional; os espaços democráticos (reuniões de equipe, conselhos locais e distritais, colegiado gestor etc.); o apoio matricial, principalmente em saúde mental. Entretanto, existem aquelas que produzem alienação, como o afastamento 
das atividades de planejamento; a fragmentação do cuidado; a predominância do modelo biomédico. Há ainda a resistência ou falta de interesse de muitos médicos pela vida institucional, certamente relacionada ao papel social ocupado por essa categoria profissional, de um suposto saber neutro e inquestionável, que por sua vez diz respeito às relações de poder na estrutura social brasileira.

É importante ressaltar, ainda, que o fato de existirem modalidades distintas de exercício profissional entre sujeitos submetidos à mesma conjuntura econômico-social, a um processo de formação semelhante, trabalhando em um mesmo contexto e na mesma instituição, nos remete ao conceito de coprodução de sujeitos e do contexto desenvolvido por Campos (2010). Isto é, essas diferenças nas formas de alienação e de envolvimento, ou até de engajamento, entre os médicos participantes da pesquisa resultam tanto do protagonismo distinto das pessoas quanto da heterogeneidade e das contradições das instâncias de determinação estrutural.

Essa constatação nos leva a reiterar nossa reflexão anterior de que, no serviço público de saúde, a alienação que resulta de uma relação saúde-sociedade capitalista é confrontada por práticas contra-hegemônicas de produção do cuidado e por formas de organização do trabalho que pretendem ser democráticas, ainda que nem sempre o sejam. Tais práticas podem implicar a construção de dinâmicas alternativas à ordem alienada do capital, uma vez que é no cotidiano que se produz a consciência da alienação e é a partir dela, sob a diuturna tensão da discussão, da reflexão e do compartilhamento, que os seres sociais serão capazes de autotranscender positivamente a alienação.

\section{Colaboradores}

Lilian Soares Vidal Terra foi responsável pela dissertação de mestrado que serviu de base à elaboração deste artigo e por sua redação, discussão dos resultados, revisão e aprovação da versão final. Gastão Wagner de Sousa Campos, além de orientar a pesquisa, colaborou na elaboração do artigo, em sua revisão e na aprovação da versão final.

\section{Financiamento}

A pesquisa de mestrado foi desenvolvida com bolsa de fomento do Conselho Nacional de Desenvolvimento Científico e Tecnológico (CNPq). 


\section{ALIENACIÓN DEL TRABAJO MÉDICO:TENSIONES SOBRE EL MODELO BIOMÉDICO Y EL DIRECTIVISMO EN LA ATENCIÓN PRIMARIA}

Resumen Con base en la observación que la pérdida de autonomía ante el mercado de capital y el directivismo contribuyó para el surgimiento de la alienación en el trabajo médico en el Sistema Único de Salud Brasileño, buscamos analizar cómo se da este fenómeno en la atención primaria de la salud. En el 2015 y 2016, entrevistamos y observamos el trabajo de 15 médicos del municipio de Campinas (São Paulo), reflexionando al respecto de la autonomía profesional, clínica y la gestión sobre el trabajo médico. El análisis se realizó a través de la construcción de relatos por núcleos temáticos, con base en la referencia teórica marxista y los principales estudios acerca de la profesión médica en Brasil. A partir de semejanzas en los discursos, forma de trabajo y grado de alienación, dividimos a los médicos en cuatro modalidades: militante, sacerdote, misionario y tecnoburócrata. Concluimos que algunas dinámicas profundizan la alienación: el alejamiento de la planificación; la fragmentación del cuidado; el predominio del modelo biomédico. Por su parte, algunas características de la atención primaria se relacionan un menor grado de alienación: la práctica ampliada en el territorio y menos enfocada en acciones programáticas; la conformación de equipos; el diálogo y el intercambio de conocimientos; la mayor participación de los usuarios en el propio cuidado y en el servicio de salud.sigualdad.

Palavras clave proceso de trabajo en salud; atención primaria de la salud; médicos; alienación (filosofía).

\section{Referências}

AGUIAR, Katia F.; ROCHA, Marisa L. Práticas universitárias e a formação sócio-política. Anuário do Laboratório de Subjetividade e Política, Niterói, n. 3/4, p. 97-112, 1997.

BALIBAR, Etiènne. As ideologias pseudomarxistas da alienação. Cadernos Cemarx, Campinas, n. 7, p. 17, 2014.

BULMER, Michael. Sociological research methods. Londres: MacMillan, 1977.

CAMPOS, Gastão W. S. Subjetividade e administração de pessoal: considerações sobre modos de gerenciar o trabalho em equipes de saúde. In: MEHRY, Emerson E.; CAMPOS, Rosana T. O. (orgs.). Agir em saúde: um desafio para o público. São Paulo: Hucitec, 1997. p. 229-266.

CAMPOS, Gastão W. S. Equipes de referência e apoio especializado matricial: um ensaio sobre a reorganização do trabalho em saúde. Ciência \& Saúde Coletiva, Rio de Janeiro, v. 4, n. 2, p. 393-403, 1999.

CAMPOS, Gastão W. S. Cogestão e neoartesanato: elementos conceituais para repensar o trabalho em saúde combinando responsabilidade e autonomia. Ciência \& Saúde Coletiva, Rio de Janeiro, v. 15, n. 5, p. 2.337-2.344, 2010.

CAMPOS, Gastão W. S. Um método de análise e cogestão de coletivos. São Paulo: Hucitec, 2013.

COLEGIADO DE GESTORES DO DEPARTAMENTO REGIONAL DE SAÚDE VII. Mapa de saúde da região de saúde de Campinas. 2016. Disponível em: <http://www.saude.campinas. sp.gov.br/rel_gestao/Mapa_da_Saude_RS_Campinas_vl_0.pdf>. Acesso em: 12 jul. 2016.

COLEGIADO DE GESTORES DA SECRETARIA MUNICIPAL DE SAÚDE DE CAMPINAS. Pro- 
jeto Paideia de Saúde da Família. Campinas, 2001. Disponível em: <http://2009.campinas. sp.gov.br/saude/diretrizes.htm $>$. Acesso em 10 jul. 2015.

\section{CONSELHO REGIONAL DE MEDICINA DO} ESTADO DE SÃO PAULO (CREMESP). Demografia médica do estado de São Paulo: relatório de pesquisa/dezembro de 2012. Disponível em: $<$ https://www.cremesp.org.br/?siteAcao $=$ Cen troDados\&acao=detalhes_capitulos\&cod_capitulo=6 > . Acesso em: 15 mar. 2016.

DONNANGELO, Maria C. F. Medicina e sociedade. 2. ed. São Paulo: Hucitec, 2011.

GOMES, Rogério M. Trabalho médico e alienação: as transformações das práticas médicas e suas implicações para os processos de humanização/ desumanização do trabalho em saúde. Tese (Doutorado em Medicina Preventiva) - Faculdade de Medicina, Universidade de São Paulo, São Paulo, 2010.

GOMES, Romeu. Análise e interpretação de dados de pesquisa qualitativa. In: MINAYO, Maria C. S. Pesquisa social: teoria, método e criatividade. 29. ed. Petrópolis: Vozes, 2010. p. 80-111.

GUBA, Egon; LINCOLN, Yvonna. Fourth generation evaluation. Newbury Park, CA: Sage Publications, 1989.

INSTITUTO BRASILEIRO DE GEOGRAFIA E ESTATÍSTICA (IBGE). Estimativas da população residente nos municípios brasileiros com data referência em $1^{\circ}$ de julho de 2016. Disponível em: <ftp://ftp.ibge.gov.br/ Estimativas_de_Populacao/Estimativas_2016/ estimativa_dou_2016_20160913.pdf > . Acesso em: 16 jan. 2017.

KONDER, Leandro. Marxismo e alienação. 2. ed. São Paulo: Expressão Popular, 2009.

LUKÁCS, György. O fenômeno da reificação. In: LUKACS, György (org.). História e consciência de classe. São Paulo: Martins Fontes, 2003. p. 194-240.
MARX, Karl. Manuscritos econômico-filosóficos. São Paulo: Boitempo, 2010.

MESZÁROS, Istvan. Teoria da alienação em Marx. São Paulo: Boitempo, 2016.

MINAYO, Maria C. S. O desafio do conhecimento: pesquisa qualitativa em saúde. São Paulo: Hucitec, 2006.

MOTA, André; SCHRAIBER, Lilia B. Medicina sob as lentes da história: reflexões teóricometodológicas. Ciência \& Saúde Coletiva, Rio de Janeiro, v. 19, n. 4, p. 1.085-1.094, 2014.

ONOCKO-CAMPOS, Rosana T.; FURTADO, Juarez P. Narrativas: utilização na pesquisa qualitativa em saúde. Revista de Saúde Pública, São Paulo, v. 42, n. 6, p. 1.090-1.096, 2008.

PASSOS, Eduardo; BARROS, Regina B. A construção do plano da clínica e o conceito de transdisciplinaridade. Psicologia: teoria e pesquisa, Brasília, v. 16, n. 1, p. 71-79, 2000.

PAULON, Simone M. A análise de implicação com ferramenta na pesquisa-intervenção. Psicologia e Sociedade, Porto Alegre, v. 17, n. 3, p. 18-25, set.-dez. 2005.

PEDUZZI, Marina. Mudanças tecnológicas e seu impacto no processo de trabalho em saúde. Trabalho, Educação e Saúde, Rio de Janeiro, v. 1, n. 1, p. 75-91, 2002.

RANIERI, Jesus J. A câmara escura: alienação e estranhamento em Marx. São Paulo: Boitempo, 2001.

ROCHA, Marisa L.; AGUIAR, Katia F. Pesquisaintervenção e a produção de novas análises. Psicologia, Ciência e Profissão, Brasília, v. 23, n. 4, p. 64-73, 2003.

SCHRAIBER, Lilia B. O médico e suas interações: a crise dos vínculos de confiança. São Paulo: Hucitec, 2008.

SCHRAIBER, Lilia B.; MENDES-GONÇALVES, Ricardo B. Necessidades de saúde e atenção 
primária. In: SCHRAIBER, Lilia B.; NEMES, Marla I. B.; MENDES-GONÇALVES, Ricardo B. (orgs.). Saúde do adulto: programas e ações na unidade básica. 2. ed. São Paulo: Hucitec, 2000. p. 29-46.

SOUZA, Helton S. A interpretação do trabalho em enfermagem no capitalismo financeirizado: um estudo na perspectiva teórica do fluxo tensionado. Dissertação (Mestrado em Saúde Pública) - Faculdade de Saúde Pública, Universidade de São Paulo, São Paulo, 2015.

THIOLLENT, Michel. Metodologia da pesquisaação. 7. ed. São Paulo: Cortez, 1996. 